\title{
Valorisation of side streams from wheat milling and confectionery industries for consolidated production and extraction of microbial lipids
}

Article

Accepted Version

Tsakona, S., Skiadaresis, A. G., Kopsahelis, N., Chatzifragkou, A., Papanikolaou, S., Kookos, I. K. and Koutinas, A. A. (2016) Valorisation of side streams from wheat milling and confectionery industries for consolidated production and extraction of microbial lipids. Food Chemistry, 198. pp. 85-92. ISSN 0308-8146 doi:

https://doi.org/10.1016/j.foodchem.2015.11.031 Available at https://centaur.reading.ac.uk/46913/

It is advisable to refer to the publisher's version if you intend to cite from the work. See Guidance on citing.

Published version at: http://www.sciencedirect.com/science/article/pii/S030881461530176X

To link to this article DOI: http://dx.doi.org/10.1016/j.foodchem.2015.11.031

Publisher: Elsevier

All outputs in CentAUR are protected by Intellectual Property Rights law, including copyright law. Copyright and IPR is retained by the creators or other copyright holders. Terms and conditions for use of this material are defined in the End User Agreement. 


\section{www.reading.ac.uk/centaur}

\section{CentAUR}

Central Archive at the University of Reading

Reading's research outputs online 


\section{Accepted Manuscript}

Valorisation of side streams from wheat milling and confectionery industries for consolidated production and extraction of microbial lipids

Sofia Tsakona, Argyrios G. Skiadaresis, Nikolaos Kopsahelis, Afroditi Chatzifragkou, Seraphim Papanikolaou, Ioannis K. Kookos, Apostolis A. Koutinas

PII: S0308-8146(15)30176-X

DOI: http://dx.doi.org/10.1016/j.foodchem.2015.11.031

Reference: FOCH 18372

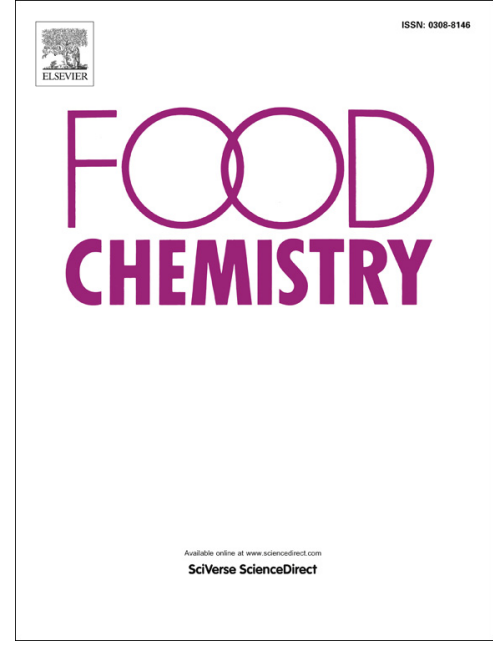

To appear in:

\section{Food Chemistry}

Received Date: $\quad 6$ May 2015

Revised Date: $\quad 20$ October 2015

Accepted Date: $\quad 6$ November 2015

Please cite this article as: Tsakona, S., Skiadaresis, A.G., Kopsahelis, N., Chatzifragkou, A., Papanikolaou, S., Kookos, I.K., Koutinas, A.A., Valorisation of side streams from wheat milling and confectionery industries for consolidated production and extraction of microbial lipids, Food Chemistry (2015), doi: http://dx.doi.org/10.1016/ j.foodchem.2015.11.031

This is a PDF file of an unedited manuscript that has been accepted for publication. As a service to our customers we are providing this early version of the manuscript. The manuscript will undergo copyediting, typesetting, and review of the resulting proof before it is published in its final form. Please note that during the production process errors may be discovered which could affect the content, and all legal disclaimers that apply to the journal pertain. 


\section{Valorisation of side streams from wheat milling and confectionery industries for consolidated production and extraction of microbial lipids}

Sofia Tsakona ${ }^{1}$, Argyrios G. Skiadaresis ${ }^{1}$, Nikolaos Kopsahelis ${ }^{1}$, Afroditi Chatzifragkou ${ }^{2}$, Seraphim Papanikolaou ${ }^{1}$, Ioannis K. Kookos ${ }^{3}$ and Apostolis A. Koutinas, ${ }^{1, *}$

${ }^{1}$ Department of Food Science and Human Nutrition, Agricultural University of Athens, Iera Odos 75, 11855, Athens, Greece

2 Department of Food and Nutritional Sciences, University of Reading, Whiteknights, Reading, RG6 6AD, UK

${ }^{3}$ Department of Chemical Engineering, University of Patras, 26504, Patras, Rio, Greece

Running Title: Food waste valorisation for microbial oil production

*Correspondence concerning this manuscript to Dr. Apostolis A. Koutinas, Laboratory of Food Process Engineering, Processing and Preservation of Agricultural Products, Department of Food Science and Human Nutrition, Agricultural University of Athens, tel./fax: +30-210-5294729, e-mail address: akoutinas@ aua.gr 


\begin{abstract}
Crude enzymes produced via solid state fermentation (SSF) using wheat milling by-products have been employed for both fermentation media production using flour-rich waste (FRW) streams and lysis of Rhodosporidium toruloides yeast cells. Filter sterilization of crude hydrolysates was more beneficial than heat sterilization regarding yeast growth and microbial oil production. The initial carbon to free amino nitrogen ratio of crude hydrolysates was optimized $(80.2 \mathrm{~g} / \mathrm{g})$ in fed-batch cultures of $R$. toruloides leading to a total dry weight of 61.2 g/L with microbial oil content of $61.8 \%(w / w)$. Employing a feeding strategy where the glucose concentration was maintained in the range of $12.2-17.6 \mathrm{~g} / \mathrm{L}$ led to the highest productivity $(0.32 \mathrm{~g} / \mathrm{L} \cdot \mathrm{h})$. The crude enzymes produced by SSF were utilised for yeast cell treatment leading to simultaneous release of around $80 \%$ of total lipids in the broth and production of a hydrolysate suitable as yeast extract replacement.
\end{abstract}

Keywords: Food waste valorisation, Bioprocess development, Rhodosporidium toruloides, Microbial oil, Enzymatic cell lysis 


\section{INTRODUCTION}

Waste and by-product streams are generated along any food supply chain starting from agricultural production up to consumption of food products. Flour-rich waste (FRW) streams are produced by various industrial sectors, including the categories manufacture of bread, fresh pastry goods and cakes (PRODCOM code 10.71), manufacture of rusks, biscuits and preserved pastry goods and cakes (PRODCOM code 10.72) and food preparations for infants (PRODCOM 10.86.10.60 and 10.86.10.70) as have been classified by the PRODCOM List 2013 (Anonymous 2014). Bran-rich wheat milling by-products are produced mainly by the category manufacture of grain mill products (PRODCOM code 10.61). To illustrate the approximate quantities of annual waste capacities produced in Europe, it is mentioned that the losses and wastes generated along the wheat and rye supply chains in Europe are: a) $1.45 \times 10^{6}$ $\mathrm{t}$ at agricultural production, b) $2.56 \times 10^{6} \mathrm{t}$ at postharvest handling and storage, c) $7.45 \times 10^{6} \mathrm{t}$ during industrial bread baking, d) $1.34 \times 10^{6} \mathrm{t}$ during distribution, and e) $16.43 \times 10^{6} \mathrm{t}$ at the consumption stage (Gustavsson, Cederberg, Sonesson, \& Emanuelsson, 2013). The current trend of policy development for future waste management in Europe focus on the classification of preventable and non-preventable wastes along the food supply chains. Reduction of food losses will focus on the preventable fraction, while the non-preventable fraction could be employed as feedstock to support the growth of bio-economy sectors, including the production of bio-based chemicals, such as microbial oil. The lipids produced by oleaginous yeasts have a similar fatty acid composition to vegetable oils and therefore can be used for the production of various derivatives including fatty acids, glycerol, fatty acid esters and fatty alcohols. Therefore, microbial lipids could be used as a potential alternative to vegetable oils for the production of various oleochemicals including lubricants, wax esters, surfactants, polymers and plastics (Naik, Goud, Rout, \& Dalai, 2010). 
Wheat milling by-products could be used as the sole substrate for the production of amylolytic and proteolytic enzymes by Aspergillus awamori via solid state fermentation (SSF) (Tsakona et al., 2014). These enzymes can be subsequently used for the production of nutrient-rich hydrolysates from FRW streams that were sufficient for microbial oil production by the oleaginous yeast Lipomyces starkeyi (Tsakona et al., 2014). It was justified that FRW hydrolysates constitute a nutrient complete fermentation medium that does not require any supplementation with commercial nutrient sources (e.g. yeast extract, inorganic salts). The utilization of yeast extract as nitrogen source increases the cost of microbial oil production by $6 \%$ at a production cost of approximately $\$ 3.4$ per $\mathrm{kg}$ that was estimated at $10,000 \mathrm{t}$ of annual production capacity, negligible cost of glucose, bioreactor productivity of $0.54 \mathrm{~g} /(\mathrm{L} \cdot \mathrm{h})$, total dry weight (TDW) of $106.5 \mathrm{~g} / \mathrm{L}$ and microbial oil content of $67.5 \%$ (w/w) (Koutinas, Chatzifragkou, Kopsahelis, Papanikolaou, \& Kookos, 2014). Therefore, utilization of FRW hydrolysates could eliminate this expenditure.

Besides L. starkeyi, Rhodosporidium toruloides is another promising strain for the production of microbial lipids. This strain has been mainly studied with commercial or crude carbon sources supplemented with commercial nutrient sources such as yeast extract. The potential of $R$. toruloides to produce microbial oil using entirely crude renewable resources as nutrientcomplete fermentation media has been reported in limited studies. Yang et al. (2015) reported the production of $16.6,14.6$ and $12.9 \mathrm{~g} / \mathrm{L}$ of microbial lipids in three successive fermentations carried out with $R$. toruloides Y4 cultivated on recycled yeast cell mass hydrolysates and 70 $\mathrm{g} / \mathrm{L}$ of initial glucose concentration. The utilization of spent yeast from breweries has been investigated as a crude source of nutrients for the cultivation of Cryptococcus curvatus leading to the production of $50.4 \mathrm{~g} / \mathrm{L}$ of TDW and $37.7 \%(\mathrm{w} / \mathrm{w})$ of microbial oil content (Ryu et al., 2013). Thiru, Sankh, \& Rangaswamy (2011) reported the production of $69.2 \mathrm{~g} / \mathrm{L}$ of 
TDW with an intracellular microbial oil content of $48 \%(w / w)$ by replacing baker's yeast autolysate and malt extract with autolysates of de-oiled yeast cells combined with crude glycerol and corn steep liquor.

The initial ratio of carbon to nitrogen and the feeding strategy employed play a crucial role on microbial oil production. Wiebe, Koivuranta, Penttilä, \& Ruohonen (2012) reported the production of TDW in the range of $35-47 \mathrm{~g} / \mathrm{L}$ with intracellular lipid content of $50-75 \%$ (w/w) in fed-batch cultures of $R$. toruloides using different feeding strategies including either provision of nitrogen source at the beginning of fermentation and no supply of nitrogen source during feeding or maintaining the same $\mathrm{C} / \mathrm{N}$ ratios of 65 or 80 during batch fermentation and feeding stages. The highest intracellular lipid content was achieved in cultures where no nitrogen source was supplied during feeding, while higher TDW were achieved when a constant $\mathrm{C} / \mathrm{N}$ ratio of 65 or 80 was maintained throughout fermentation. The strain $R$. toruloides $\mathrm{Y} 4$ has been cultivated on fed-batch mode using commercial glucose and nutrient supplements under pulsed feeding of nitrogen-free media leading to the production of $71.8 \mathrm{~g} / \mathrm{L}$ of intracellular lipids with a productivity of $0.54 \mathrm{~g} /(\mathrm{L} \cdot \mathrm{h})(\mathrm{Li}, \mathrm{Zhao}, \&$ Bai, 2007). Zhao, Hu, Wu, Shen, \& Zhao (2011) reported that the highest DCW (127.5 g/L), lipid concentration $(78.8 \mathrm{~g} / \mathrm{L})$ and productivity $(0.57 \mathrm{~g} / \mathrm{L} \cdot \mathrm{h})$ when a constant glucose concentration of around $5 \mathrm{~g} / \mathrm{L}$ was maintained during the feeding stage. The effect of carbon to free amino nitrogen (FAN) ratio and the application of different feeding strategies on microbial oil production have not been studied in the case of crude hydrolysates derived from renewable resources.

Downstream separation of microbial lipids is another crucial issue hindering the implementation of large-scale processes. The yeast cells should be initially separated from the 
fermentation broth via filtration-based unit operations. Cell disruption combined with solvent extraction is the conventional methodology followed for separation and purification of microbial lipids. Cell disruption can be achieved by various methods including high pressure homogenization, bead milling, swelling by osmotic pressure, and acidic or alkaline treatment (Li, Zhao, \& Bai, 2007; Lee et al., 2010; Koutinas, Chatzifragkou, Kopsahelis, Papanikolaou, \& Kookos, 2014). Jin, Yang, Hu, Shen, \& Zhao (2012) reported a 96.6\% separation of microbial lipids from $R$. toruloides cells at room temperature and atmospheric pressure directly after fermentation without filtration of yeast cells via pre-treatment with microwave followed by enzymatic hydrolysis with the recombinant $\beta$-1,3-glucomannanase plMAN5C and extraction with ethyl acetate. Crude enzymes produced via solid state fermentation of renewable resources have never been used for yeast cell disruption and removal of microbial lipids.

This study focuses on the optimization of the initial carbon to free amino nitrogen ratio in fedbatch cultures using the oleaginous yeast $R$. toruloides cultivated on crude FRW hydrolysates. Various feeding strategies have been employed at the optimum carbon to free amino nitrogen ratio. A consolidated bioprocess is proposed where the crude enzymes produced by SSF of wheat milling by-products could be employed for the production of FRW hydrolysates and the disruption of yeast cells leading to the release of microbial lipids in the aqueous suspension.

\section{Materials and Methods}

\subsection{Microorganisms}

The SSF employed for the production of crude enzyme consortia were conducted with the fungal strain Aspergillus awamori 2B.361 U2/1 that was originally obtained from ABM 
Chemicals, Ltd. (Woodley, Cheshire, UK) and was kindly provided by Professor Colin Webb (University of Manchester, UK). The purification and sporulation of A. awamori spores have been described by Koutinas et al. (2001). Storage of fungal spores was carried out in slopes at $4^{\circ} \mathrm{C}$ containing $5 \%(\mathrm{w} / \mathrm{v})$ wheat bran and $2 \%(\mathrm{w} / \mathrm{v})$ agar.

Submerged fermentations for the production of microbial oil were carried out with the oleaginous yeast strain Rhodosporidium toruloides DSM 4444. Agar slopes containing glucose $(10 \mathrm{~g} / \mathrm{L})$, yeast extract $(10 \mathrm{~g} / \mathrm{L})$, peptone $(10 \mathrm{~g} / \mathrm{L})$ and agar $(2 \%$, w/v) were used for maintenance of this strain at $4^{\circ} \mathrm{C}$. The same composition of nutrients was used for the preparation of fermentation inocula $(50 \mathrm{~mL})$ in $250 \mathrm{~mL}$ Erlenmeyer flasks.

\subsection{Raw materials and fermentation media}

The solid substrate used in the SSF carried out with the fungal strain A. awamori was wheat milling by-products that contained $12 \%$ starch, $20 \%$ protein, $1.1 \%$ phosphorus and $9.7 \%$ moisture (w/w). The FRW streams used for the production of fermentation media using the crude enzyme consortia produced by SSF were supplied by Jotis S.A., a Greek confectionery industry. The FRW streams produced during the manufacturing process of food for infants contained $84.8 \%$ starch, $7.3 \%$ protein and $5 \%$ moisture $(\mathrm{w} / \mathrm{w})$.

The production of enzyme consortia via SSF and FRW hydrolysates was carried out as was described by Tsakona et al. (2014). SSF of A. awamori was carried out in $250 \mathrm{~mL}$ Erlenmeyer flasks at $30^{\circ} \mathrm{C}$ using $5 \mathrm{~g}$ of wheat milling by-products as substrate. Sterilisation of each flask was carried out at $121^{\circ} \mathrm{C}$ for 20 min prior to inoculation that was carried out with a fungal spore suspension of $2 \times 10^{6}$ spores per mL. After 3 days, SSF solids were suspended in 500 $\mathrm{mL}$ sterilised tap water and were subsequently macerated using a kitchen blender. After 
centrifugation $(3,000 \times g$ for $10 \mathrm{~min})$ of the aqueous suspension, the supernatant was transferred in $1 \mathrm{~L}$ Duran bottles that contained varying FRW concentrations in order to achieve the desired carbon to FAN ratio. Magnetic stirrers were used for mixing of the suspension. Hydrolysis of FRW was carried out at $55^{\circ} \mathrm{C}$ and uncontrolled $\mathrm{pH}$ conditions. The initial glucoamylase and protease activities were around $0.5 \mathrm{U} / \mathrm{mL}$ and $8 \mathrm{U} / \mathrm{mL}$, respectively.

Upon completion of enzymatic hydrolysis, solids were separated via centrifugation $(3,000 \times g$ for $10 \mathrm{~min}$ ). The supernatant was filtered (Whatman No1) to remove any remaining insoluble materials. FRW hydrolysates used as fermentation media were either autoclaved $\left(121^{\circ} \mathrm{C}\right.$ for 15 min) or filter-sterilised using a $0.2 \mu \mathrm{m}$ filter unit (Polycap TM AS, Whatman Ltd.). The pH of the hydrolysate was adjusted to the optimum $\mathrm{pH}$ value of 6.0 for yeast growth using $10 \mathrm{M}$ $\mathrm{NaOH}$.

\subsection{Bioreactor fermentations}

The bioreactor (New Brunswick Scientific Co, USA) employed in batch and fed-batch fermentations had a total volume of $3 \mathrm{~L}$ and a working volume of $1.5 \mathrm{~L}$. The temperature, aeration and $\mathrm{pH}$ value were controlled at $27^{\circ} \mathrm{C}, 1.5 \mathrm{vvm}$ and $6.0 \pm 0.1$ by automatic addition of $10 \mathrm{M} \mathrm{NaOH}$, respectively. A $10 \%(\mathrm{v} / \mathrm{v})$ inoculum was employed using a $24 \mathrm{~h}$ exponential preculture. The agitation rate was controlled in the range of $150-500 \mathrm{rpm}$. FRW hydrolysates were used at the beginning of all batch and fed-batch fermentations.

Fed-batch fermentations were focused on the optimisation of the initial carbon to FAN ratio $(100.4,80.2,58.2,47.2$ and $31.9 \mathrm{~g} / \mathrm{g})$. The carbon corresponded to the carbon content in glucose, whereas the FAN corresponded to the nitrogen contained in the free amino groups of amino acids and peptides in the hydrolysate. Different FRW hydrolysates were mixed in order 
to obtain the appropriate $\mathrm{C} / \mathrm{FAN}$ ratio in each fermentation. A glucose concentration in the range of $55-60 \mathrm{~g} / \mathrm{L}$ was used at the beginning of all fed-batch fermentations. The initial FAN concentrations employed in the five fed-batch fermentations were 220, 294, 397, 492 and 682 mg/L. A concentrated glucose solution $(70 \%$, w/v) was used as feeding medium when the glucose concentration was reduced to less than $20 \mathrm{~g} / \mathrm{L}$. In one fed-batch fermentation, the feeding medium contained $70 \%(\mathrm{w} / \mathrm{v})$ of glucose concentration and $1 \%(\mathrm{w} / \mathrm{v})$ of yeast extract concentration, equivalent to around $500 \mathrm{mg} / \mathrm{L}$ of FAN concentration. The selected feeding mode was either based on consecutive pulses or targeted the maintenance of glucose concentration at approximately the same level. The duration of each fed-batch fermentation was up to $150 \mathrm{~h}$ when both TDW and lipid production were terminated.

Fermentation samples were initially centrifuged $(9,000 \times g$ for $10 \mathrm{~min})$ to separate yeast cells from the supernatant. The supernatant was used for the analysis of glucose, FAN and inorganic phosphorus (IP), while the yeast biomass was used to determine the TDW and intracellular lipids. Fermentations were carried out in duplicates and the respective analyses in triplicates. Data presented are the mean values of those measurements.

\subsection{Disruption of yeast cells}

Yeast cell disruption was investigated either via autolysis or enzymatic hydrolysis using the crude enzyme consortia produced via SSF of A. awamori. The disruption of yeast cells was identified by quantifying the dry weight at different reaction times and by analysing the FAN concentration in the reaction medium that was increased due to protein hydrolysis. The reduction of total dry weight and the increasing FAN concentration indicated yeast cell disruption and protein hydrolysis. The lipids were quantified in both the yeast cells and the aqueous suspension. 
The yeast cells were harvested after the end of a batch fermentation in FRW hydrolysates. The initial yeast cell concentration in both autolysis and enzymatic hydrolysis reaction was $28.5 \mathrm{~g} / \mathrm{L}$ with an intracellular lipid content of $32.28 \%(w / w)$. Autolysis of yeast cells was carried out at $50^{\circ} \mathrm{C}$ and uncontrolled $\mathrm{pH}$. In the case of enzymatic hydrolysis of yeast cells, the enzyme suspension was produced following the same protocol presented above using an enzyme-rich aqueous extract that was produced by suspending SSF solids in $250 \mathrm{~mL}$ sterilised tap water. The initial protease activity in enzymatic cell lysis was $13.5 \mathrm{U} / \mathrm{mL}$. Prior to initiation of enzymatic lysis of yeast cells, the fermentation broth was boiled at $100^{\circ} \mathrm{C}$ for 2 min, in order to inactivate endogenous enzymes and prevent autolysis of yeast cells. Then, the aqueous extract rich in crude enzyme consortia produced via SSF of A. awamori was added to the cell suspension and the mixture was incubated at $50^{\circ} \mathrm{C}$ under agitation at $200 \mathrm{rpm}$ to achieve cell lysis. An additional sample of heat-treated cells without crude enzymes was used as control. After the end of incubation, the mixture was centrifuged $\left(9000 \times g, 4^{\circ} \mathrm{C}, 10 \mathrm{~min}\right)$, the supernatant was removed and Folch solution was added to the cell debris. After centrifugation of the mixture $\left(9000 \times g, 4^{\circ} \mathrm{C}, 5 \mathrm{~min}\right)$, the solvent phase was removed for the analysis of lipids and the residual cell debris was dried at $105^{\circ} \mathrm{C}$ for $24 \mathrm{~h}$ for the determination of lipid-free yeast mass. The lipids released in the liquid were analysed after removal of the water via lyophilisation and extracting the remaining lipids using a Folch solution.

\subsection{Analytical methods}

The assays employed for the determination of glucoamylase and protease activities have been presented by Tsakona et al (2014). One unit (U) of glucoamylase activity was defined as the amount of enzyme that releases $1 \mathrm{mg}$ glucose in $1 \mathrm{~min}$ under the assay conditions. One unit 
(U) of proteolytic activity was defined as the amount of enzyme that releases $1 \mu \mathrm{g}$ FAN in 1 min under the reaction conditions.

FAN concentration was quantified according to the ninhydrin colorimetric method promulgated in the European Brewery Convention (Lie, 1973). IP concentration was quantified by the ammonium molybdate spectrophotometric method (Harland \& Harland, 1980). Glucose was analysed using a High Performance Liquid Chromatography unit (Waters 600E) equipped with an Aminex HPX-87H column $(300 \mathrm{~mm} \times 7.8 \mathrm{~mm}$, Bio-Rad, California, USA) and a differential refractometer (RI Waters 410). Operating conditions were as follows: sample volume $20 \mu \mathrm{L}$; mobile phase $0.005 \mathrm{M} \mathrm{H}_{2} \mathrm{SO}_{4}$; flow rate $0.6 \mathrm{~mL} / \mathrm{min}$; column temperature $65^{\circ} \mathrm{C}$.

TDW was determined by drying the yeast biomass at $105^{\circ} \mathrm{C}$ for $24 \mathrm{~h}$. Microbial oil was quantified according to the method proposed by Folch, Lees, \& Sloane-Stanley (1957). After disruption of dried yeast cell mass, the Folch solution, chloroform/methanol mixture at a ratio of 2:1 (v/v), was added to the cell debris. After centrifugation $\left(9000 \times g, 4^{\circ} \mathrm{C}, 5 \mathrm{~min}\right)$, the solvent phase was collected, washed with $0.88 \% \mathrm{KCl}(\mathrm{w} / \mathrm{v})$, dried with anhydrous $\mathrm{Na}_{2} \mathrm{SO}_{4}$ and evaporated under vacuum. Residual cell debris was dried at $105^{\circ} \mathrm{C}$ for $24 \mathrm{~h}$ for the determination of lipid-free cell mass.

The fatty acid profile of microbial oil was determined through the production of fatty acid methyl esters (FAME) following a two-step reaction with methanol using sodium methoxide ( $\mathrm{MeONa}$ ) and $\mathrm{HCl}$ as catalysts. The acid catalyst was used in order to esterify free fatty acids into FAME that may have been produced due to microbial oil hydrolysis by intracellular lipase. FAME were analysed by a Gas Chromatography Fisons 8060 unit equipped with a 
chrompack column $(60 \mathrm{~m} \times 0.32 \mathrm{~mm})$ and a FID detector. Helium was used as carrier gas $(2$ $\mathrm{mL} / \mathrm{min}$ ). The analysis was carried out at $200^{\circ} \mathrm{C}$ with the injection at $240^{\circ} \mathrm{C}$ and the detector at $250^{\circ} \mathrm{C}$. FAME were identified by reference to standards.

\section{Results and Discussion}

\subsection{Effect of sterilisation process}

Tsakona et al. (2014) demonstrated the development of a two stage bioprocess for the conversion of FRW streams into a generic fermentation feedstock rich in glucose and directly assimilable amino acids and peptides. Preliminary experiments showed that heat sterilisation was not an ideal process for such a complex fermentation medium. For this reason, heat sterilisation was compared with filter sterilisation in order to identify the optimum sterilisation method. Fig 1 presents the consumption of glucose and the production of TDW and lipids during cultivation of $R$. toruloides on FRW hydrolysates subjected either to heat (Fig 1a) or filter sterilisation (Fig 1b). Initial glucose concentration was around 99 and $94 \mathrm{~g} / \mathrm{L}$ respectively, whereas the initial FAN concentration was $200 \mathrm{mg} / \mathrm{L}$ in both cases. Substrate consumption was notably faster when the yeast cells were cultivated in filter sterilised media, resulting in enhanced TDW formation and lipid accumulation in shorter fermentation duration. The highest TDW in filter sterilised media was $32 \mathrm{~g} / \mathrm{L}$ with an intracellular lipid concentration of $15.2 \mathrm{~g} / \mathrm{L}$ after $51 \mathrm{~h}$. In the case of heat sterilised media, the highest lipid concentration (10.6 g/L), corresponding to $28.2 \mathrm{~g} / \mathrm{L}$ of TDW, was observed at $75 \mathrm{~h}$.

In the case of liquid media, heat sterilisation is commonly used in conventional fermentation processes, in order to ensure the elimination of endogenous microorganisms prior to media inoculation with pure microbial cultures. However, heat treatment can cause adverse effects to nutrients such as caramelisation of sugars, denaturation of proteins, inactivation of vitamins 
and other nutrients of importance for microbial growth, as well as Maillard reactions between sugars and amino groups (Berovic, 2005). In order to avoid such phenomena, separate steam sterilisation of nutrient components is usually performed. However, in the case of crude hydrolysates produced from renewable resources, as in the case of FRW hydrolysates, the latter is not applicable. In the present study, filter sterilisation proved as suitable practice for media sterilisation without compromising nutrient availability, as reflected by $R$. toruloides growth and microbial oil accumulation.

\subsection{Effect of initial C/FAN ratio in fed-batch bioreactor cultures}

One of the major targets of this study was the optimisation of the initial carbon to free amino nitrogen ratio in fed-batch bioreactor cultures using the oleaginous yeast $R$. toruloides cultivated on crude FRW hydrolysates. The fed-batch culture mode was chosen as the most promising cultivation strategy for oleaginous microorganisms that promotes high cell density cultures and high lipid production rates (Li, Zhao \& Bai, 2007; Zhang et al., 2011). An essential condition for the initiation of "de novo" lipid accumulation in oleaginous microorganisms represents the imposition of nutrient-limited cultivation conditions, with nitrogen often being the limiting factor. The concentration of nitrogen source reflects mainly the quantity of biomass formation, whereas the excess of carbon concentration largely determines the amount of accumulated lipids (Papanikolaou \& Aggelis, 2011). Consequently, the carbon-to-nitrogen $(\mathrm{C} / \mathrm{N})$ ratio is considered as a determinant factor towards cell density and lipid content during cultivation of oleaginous microorganisms. However, optimum $\mathrm{C} / \mathrm{N}$ is attributed as a strain-dependent regulatory factor and should be determined for individual strains. 
In order to obtain different C/FAN ratios, crude FRW hydrolysates were generated through appropriate enzymatic hydrolysis of FRW utilising crude enzyme consortia produced via SSF of A. awamori. It should be noted that FAN corresponds to the organic nitrogen content of the hydrolysate, deriving from free amino groups of peptides and amino acids. Cultures were initiated batchwise and when the residual glucose concentration dropped to less than $20 \mathrm{~g} / \mathrm{L}$, a concentrated glucose feeding solution was introduced intermittently in the bioreactor.

Table 1 presents the results obtained from fed-batch bioreactor fermentations of $R$. toruloides using different initial C/FAN ratios. Initial glucose concentration was kept at $55-60 \mathrm{~g} / \mathrm{L}$ and FAN concentrations ranged from 220 to $682 \mathrm{mg} / \mathrm{L}$. The best results were achieved for initial C/FAN ratio of $80.2 \mathrm{~g} / \mathrm{g}$ at $142 \mathrm{~h}$ corresponding to $61.2 \mathrm{~g} / \mathrm{L}$ of TDW with an intracellular lipid content of $61.8 \%(\mathrm{w} / \mathrm{w}$ ) (Fig 2). In this C/FAN ratio, the lipid productivity by $R$. toruloides reached $0.27 \mathrm{~g} /(\mathrm{L} \cdot \mathrm{h})$, with a corresponding lipid yield of $0.17 \mathrm{~g}$ per $\mathrm{g}$ of consumed glucose. In lower initial C/FAN ratios, the lipid content was lower, whereas the residual cell weight (RCW) values were increased. For instance, in cultures with initial C/FAN ratio of $80.2 \mathrm{~g} / \mathrm{g}$, the ratio of $\mathrm{RCW}(23.3 \mathrm{~g} / \mathrm{L})$ to $\mathrm{TDW}(61.2 \mathrm{~g} / \mathrm{L})$ was $38 \%$, while the corresponding value in cultures with initial C/FAN ratio of $47.2 \mathrm{~g} / \mathrm{g}$ was $58 \%$. The higher $\mathrm{RCW}$ at decreasing C/FAN ratio could be attributed either to the production of lipid-free yeast cell mass during $R$. toruloides growth (up to approximately 20 - $30 \mathrm{~h}$ when FAN and IP were completely consumed) or to the accumulation of endo-polysaccharides. The lowest lipid-free yeast cell concentration $(20.9 \mathrm{~g} / \mathrm{L})$ reached after the growth stage was observed at the highest $\mathrm{C} / \mathrm{FAN}$ ratio of $100.4 \mathrm{~g} / \mathrm{g}$, whereas the lipid-free yeast cell concentration at C/FAN ratios of $80.2 \mathrm{~g} / \mathrm{g}$ and $58.2 \mathrm{~g} / \mathrm{g}$ were 23.3 and $23.7 \mathrm{~g} / \mathrm{L}$, respectively. In these three cases, the RCW reached a plateau after approximately $30 \mathrm{~h}$, when lipid accumulation had been initiated. However, in the cases of C/FAN ratios of $47.2 \mathrm{~g} / \mathrm{g}$ and $31.9 \mathrm{~g} / \mathrm{g}$, the RCW trend was completely different. In 
the case of a C/FAN ratio of $47.2 \mathrm{~g} / \mathrm{g}$, the $\mathrm{RCW}$ increased up to $36.3 \mathrm{~g} / \mathrm{L}$ at $43 \mathrm{~h}$, whereas at a C/FAN ratio of $31.9 \mathrm{~g} / \mathrm{g}$ the $\mathrm{RCW}$ increased gradually up to $31.4 \mathrm{~g} / \mathrm{L}$ at $115 \mathrm{~h}$. In both cases the FAN and IP concentrations were completely consumed up to $25 \mathrm{~h}$. It has been previously demonstrated that oleaginous microorganisms are capable of accumulating endopolysaccharides (Tsakona et al., 2014; Tchakouteu et al., 2014). Therefore, the increased RCW values could be also attributed to endo-polysaccharide accumulation (Table 1). Another important parameter is the formation of carotenoids by $R$. toruloides strains (Dias et al., 2015), which was indeed observed in this study but it was not quantified. This study identified the optimum C/FAN ratio regarding lipid production. However, a more detailed evaluation of all parameters is required in order to provide the complete capabilities of this strain regarding formation of lipids, endo-polysaccharides and carotenoids. At the highest C/FAN ratio (100.4 $\mathrm{g} / \mathrm{g})$, the TDW (49 g/L) was the lowest achieved but the lipid concentration (28.2 g/L) and content $(57.5 \%, \mathrm{w} / \mathrm{w})$ were both second best demonstrating that the low nitrogen content led to relatively high lipid accumulation, but low cell growth.

The different initial C/FAN ratios had an evident effect on the specific growth rate $(\mu)$ of $R$. toluloides observed during the exponential growth phase of each fermentation (Table 1). The highest specific growth rate $\left(0.475 \mathrm{~h}^{-1}\right)$ was observed at a C/FAN ratio of $80.2 \mathrm{~g} / \mathrm{g}$. At this initial C/FAN ratio, rapid biomass formation is efficiently favoured in the yeast growth phase and lipid accumulation is triggered when FAN and IP consumption is terminated. Cultures with lower C/FAN ratios resulted in lower specific growth rate values, ranging between 0.286 $-0.18 \mathrm{~h}^{-1}$. A specific growth rate of $0.2 \mathrm{~h}^{-1}$ was observed in the fermentation that was carried out with the highest C/FAN ratio $(100.4 \mathrm{~g} / \mathrm{g})$ demonstrating that this is a rather nutrient deficient medium. 
The type of nitrogen source (i.e. inorganic or organic) present in media is acknowledged as a critical factor for oleaginous microorganisms, as it can promote "de novo" lipid synthesis in a strain-dependent manner. Lipid accumulation in $R$. toruloides is reported to be favoured in the presence of organic nitrogen sources (Evans \& Ratledge, 1984a). Evans and Ratledge (1984b) concluded that nitrogen source influences lipid production by virtue of its products of catabolism, rather than acting directly as a lipid-stimulating compound itself. In the case of $R$. toruloides CBS 14, cultivation in media supplemented with glutamate as nitrogen source resulted in increased lipid concentrations (up to $50 \%, \mathrm{w} / \mathrm{w}$ ) as opposed to cultures with ammonium salts (inorganic source of nitrogen). It was later shown that when organic compounds such as glutamate are utilised as nitrogen sources, metabolic alterations in the extent of $\mathrm{NH}_{4}{ }^{+}$release and accumulation take place that increase the intracellular concentration of $\mathrm{NH}_{4}^{+}$. The latter has an impact on the activity of phosphoro-fructokinase enzyme (PFK), responsible for the catabolic flux of carbon, by forming a stable complex with $\mathrm{NH}_{4}$, less susceptible to the inhibitory effect of citrate on PFK. This particular mechanism found in some oleaginous yeast strains, as in the case of $R$. toruloides, ensures an unrestrained carbon flow towards lipid synthesis (Evans \& Ratledge, 1985). In our case, the supplementation of amino acids and peptides to $R$. toruloides cells in conjunction with the optimum C/FAN ratio of the FRW hydrolysate significantly enhanced lipid accumulation in R. toruloides.

Besides FAN, the consumption of IP concentration was also analysed during yeast growth (Fig 2a). It should be noted that FRW hydrolysates with high initial FAN concentrations, contained similarly increased initial IP concentrations, ranging from 104 to $372 \mathrm{mg} / \mathrm{L}$. In all cases, IP consumption was carried out in parallel to FAN consumption (Fig 2a), whereas their exhaustion from the medium coincided with the onset of lipid accumulation (Fig 2b). 
Although nitrogen depletion has been mainly studied as the limiting nutrient triggering a series of intracellular biochemical events towards lipid accumulation, the limitation of other micro-nutrients can also lead to efficient lipid production. Phosphorus- or sulphur-limited conditions in carbon- and nitrogen-rich media have been reported as alternative strategies for lipid accumulation in $R$. toruloides (Wu, Hu, Jin, Zhao \& Zhao, 2010; Wu, Zhao, Shen, Wang \& Zhao, 2011). Therefore, future studies should evaluate the effect of each one of these nutrients on lipid accumulation when crude hydrolysates are used.

Table 2 shows the fatty acid profile of $R$. toruloides lipids produced in fed-batch cultures with initial C/FAN ratio of $80.2 \mathrm{~g} / \mathrm{g}$ at different fermentation times. Oleic (C18:1) and palmitic (C16:0) acids were the major fatty acids followed by stearic (C18:0) and linoleic (C18:2) acids. Minor differences were noticed in fatty acid composition during fermentation, regardless of the initial $\mathrm{C} / \mathrm{FAN}$ ratio used. The concentration of oleic and palmitic acid accounted for approximately $80 \%(\mathrm{w} / \mathrm{w})$ of the total fatty acid composition, a feature that has been previously reported for other $R$. toruloides strains cultivated in glucose-based media (Wu, Hu, Jin, Zhao, Zhao, 2010; Zhao et al., 2011).

\subsection{Effect of feeding in fed-batch bioreactor cultures}

In fed-batch cultivations of oleaginous microorganisms, the choice of the feeding strategy plays a significant role in lipid accumulation and productivity (Zhao, Hu, Shen \& Zhao, 2011). In the fed-batch fermentations presented above, an intermittent feeding strategy of a glucose-rich solution was employed in all cases. Based on the optimum initial C/FAN ratio of $80.2 \mathrm{~g} / \mathrm{g}$, two fed-batch fermentations were carried out employing two different feeding strategies focusing on either the control of residual glucose concentration in the culture (Fig 3) or the addition of a low nitrogen source besides glucose during feeding (Fig 4). 
In the first feeding strategy, the glucose concentration was maintained in the range of $12.2-$ $17.6 \mathrm{~g} / \mathrm{L}$ throughout feeding that was initiated when the glucose concentration was reduced to less than $15 \mathrm{~g} / \mathrm{L}$ (Fig 3). The time courses for glucose consumption as well as TDW and lipid production are presented in Fig 3. After $118 \mathrm{~h}$, the TDW reached $62.4 \mathrm{~g} / \mathrm{L}$ with an intracellular lipid content of $61 \%(\mathrm{w} / \mathrm{w})$, which were similar to the respective values achieved in the fermentation carried out with intermittent feeding at the same initial C/FAN ratio (Fig 2 and Table 1). However, the productivity, $0.32 \mathrm{~g} /(\mathrm{L} \cdot \mathrm{h})$, achieved by keeping an almost constant glucose concentration during feeding was higher than the case that intermittent feeding was used, i.e. $0.27 \mathrm{~g} /(\mathrm{L} \cdot \mathrm{h})$. Furthermore the glucose to lipid conversion yield $(0.185$ $\mathrm{g} / \mathrm{g}$ ) was also higher when an almost constant glucose concentration was maintained during feeding. Zhao et al. (2011) applied a continuous feeding strategy during fed-batch cultures of R. toruloides $\mathrm{Y} 4$ in defined media and highlighted that low substrate concentration (below 5 $\mathrm{g} / \mathrm{L})$ was favourable for TDW and lipid production. In these conditions, the yeast strain $R$. toruloides Y4 produced $127.5 \mathrm{~g} / \mathrm{L}$ of TDW with lipid content of $61.8 \%$ and a high lipid productivity of $0.57 \mathrm{~g} /(\mathrm{L} \cdot \mathrm{h})$ (Zhao, Hu, Wu, Shen, \& Zhao, 2011).

Although nitrogen-limitation is an essential factor that triggers lipid accumulation, nitrogen source deficiency could decrease the overall lipid productivity in cultures of oleaginous microorganisms (Zhao, Hu, Wu, Shen, \& Zhao, 2011). To identify the effect of low nitrogen supply during feeding, the second feeding strategy involved the incorporation of $1 \%$ yeast extract in the feeding solution. The optimum initial C/FAN ratio of $80.2 \mathrm{~g} / \mathrm{g}$ was used. The time courses of glucose consumption as well as TDW and lipid production are presented in Fig 4. The yeast $R$. toruloides produced $51 \mathrm{~g} / \mathrm{L}$ of TDW containing $55 \%$ (w/w) of microbial oil after $98 \mathrm{~h}$. The lipid productivity was $0.28 \mathrm{~g} /(\mathrm{L} \cdot \mathrm{h})$. Although the highest RCW observed 
was around 23-24 g/L which was similar to the one observed with feeding a solution containing only glucose (Table 2), the final lipid concentration and content were significantly lower. However, the glucose to lipid conversion yield $(0.22 \mathrm{~g} / \mathrm{g})$ was higher than the fermentation carried out with only glucose feeding. This means that glucose was diverted more efficiently towards lipid accumulation, but this was stopped prematurely compared to the fermentations carried out with only glucose feeding (Table 2). Similar results were obtained in fermentations carried out with concentrated FRW hydrolysate produced via vacuum evaporation containing a glucose concentration of $600 \mathrm{~g} / \mathrm{L}$ and a FAN concentration of $1.5 \mathrm{~g} / \mathrm{L}$ using either intermittent feeding or continuous feeding in order to maintain a constant glucose concentration during feeding (results not presented). Similar observations were reported by Saenge, Cheirsilp, Tachapattawearwrakul \& Bourtoom (2011) in fed-batch fermentations of Rhodotorula glutinis with feeding containing glycerol and ammonium sulphate. The feeding strategy should be evaluated further in the case of FRW hydrolysates in order to identify the potential to enhance microbial oil production.

Koutinas, Chatzifragkou, Kopsahelis, Papanikolaou, \& Kookos (2014) have presented the fluctuation of the unitary cost of microbial oil production at varying glucose costs considering a plant producing $10,000 \mathrm{t}$ of microbial oil per annum. At negligible cost of glucose, the unitary cost of purified microbial oil was estimated at $\$ 3.4 / \mathrm{kg}$, whereas at a glucose cost of $\$ 400 / \mathrm{t}$ the oil production cost was estimated at around $\$ 5.5 / \mathrm{kg}$ oil. In the case that FRW hydrolysates are used for fermentation media production, the cost of microbial oil production is expected to be closer to the former case if the FRW is considered at negligible market price.

\subsection{Cell disruption via enzymatic treatment}


Davies (1988) has presented detailed information on microbial oil extraction involving drying of oleaginous yeast cell mass, mixing of dried cell mass with hexane, mechanical cell disruption, separation of the lipid-rich hexane phase from the disrupted yeast cells via decanting and purification of lipids via evaporation and recycling of hexane. Similar processing schemes have been presented for the separation of various intracellular products and lipids from microalgal biomass (Molina, Belarbi, Acien, Robles, \& Chisti, 2003; Stephenson et al., 2010). Mechanical cell disruption can be achieved via bead milling or high pressure homogenisation. Jin, Yang, Hu, Shen, \& Zhao, (2012) employed microwave treatment followed by enzymatic treatment with recombinant $\beta$-1,3-glucomannanase for the extraction of lipids from the yeast mass of $R$. toruloides Y4. Cell disruption of microalgal biomass has also been investigated using various methods including mechanical methods, microwave treatment and osmotic shock (Lee, Yoo, Jun, Ahn, \& Oh, 2010).

In this study, it was evaluated the potential to disrupt $R$. toruloides cells via autolysis or by using crude enzyme consortia that were produced via SSF of A. awamori cultivated on wheat milling by-products. The initial concentration of the yeast cells used was $28.5 \mathrm{~g} / \mathrm{L}$ with an intracellular lipid concentration of $9.2 \mathrm{~g} / \mathrm{L}$. Figure 5a shows that around $20 \%$ of total lipids were released in the liquid after simple heat treatment of the fermentation broth at $50^{\circ} \mathrm{C}$ leading to initiation of autolysis. The process of autolysis is indicated by the increasing FAN concentration that was gradually increased up to $45 \mathrm{mg} / \mathrm{L}$ after $10 \mathrm{~h}$. The reduction of TDW during autolysis was only $22.5 \%$. It should be pointed out that further optimisation could improve cell disruption and lipid release in the surrounding liquid. Figure $5 \mathrm{~b}$ shows that around $80 \%$ of total lipids were released in the broth when crude enzymes produced by $A$. awamori were used. Around three times higher FAN concentration (145.8 mg/L) was produced than in the case of yeast cell autolysis. The reduction of TDW during enzymatic cell 
lysis was around $52 \%$. These results indicate that it is possible to utilise the crude enzymes produced by $A$. awamori for $R$. toruloides cell disruption. The separation of lipids from the aqueous suspension could be achieved by solvent extraction, such as ethyl acetate as was suggested by Jin, Yang, Hu, Shen, \& Zhao (2012).

The proposed consolidated process could eliminate the need for cell removal from fermentation broth via filtration and drying of the yeast cell mass that is employed in conventional processes. Furthermore, lipid separation is achieved simultaneously with yeast cell hydrolysis producing a nutrient rich suspension that could be recycled in the fermentation stage. In this way, the enzymes produced via SSF could be employed for both the production of FRW hydrolysates, the separation of lipids from the yeast cell mass and the hydrolysis of yeast cells for nutrient recycling. However, the preliminary results presented in this study should be optimised further in order to evaluate the potential of combined yeast cell hydrolysis and lipid removal from the broth via liquid-liquid extraction.

\section{Conclusion}

Filter sterilisation has been identified as a preferred sterilisation method of FRW hydrolysates than heat treatment. The initial C/FAN ratio was subsequently optimised regarding microbial oil production in fed-batch cultures of $R$. toruloides. A consolidated bioprocess was developed where the crude enzymes produced by SSF of wheat milling by-products could be employed not only for the production of FRW hydrolysates but also for the disruption of yeast cells and the release of microbial lipids.

\section{Acknowledgments}


This work is funded by the research project "NUTRI-FUEL" (09SYN-32-621), implemented within the National Strategic Reference Framework (NSRF) 2007-2013 and co-financed by National (Greek Ministry - General Secretariat of Research and Technology) and Community Funds (E.U. - European Social Fund). This work is also included in the Cost Action TD1203 entitled "Food waste valorisation for sustainable chemicals, materials \& fuels (EUBis)". 


\section{References}

Anonymous,

2014.

PRODCOM

List

2013.

http://ec.europa.eu/eurostat/ramon/nomenclatures/index.cfm?TargetUrl=LST_NOM_DTL\&St $\underline{\text { rNom=PRD_2013\&StrLanguageCode }=E N \& I n t P c K e y=\& S t r L a y o u t C o d e=H I E R A R C H I C}$

(visited: 04/2015).

Berovic, M. (2005). Sterilisation in biotechnology. Biotechnology annual review, 11, 257279.

Davies, R. J. (1988). Yeast oil from cheese whey-process development. In: Moreton, R. S., editor. Single cell oil. London: Longman; p. 99-145.

Dias, C., Sousa, S., Caldeira, J., Reis, A., \& Lopes da Silva, T. (2015). New dual-stage pH control fed-batch cultivation strategy for the improvement of lipids and carotenoids production by the red yeast Rhodosporidium toruloides NCYC 921. Bioresource Technology, $189,309-318$.

Evans, C. T., \& Ratledge, C. (1984a). Effect of nitrogen source on lipid accumulation in oleaginous yeasts. Journal of General Microbiology, 130, 1693-1704.

Evans, C. T., \& Ratledge, C. (1984b). Influence of nitrogen metabolism on lipid accumulation by Rhodosporidium toruloides CBS 14. Journal of General Microbiology, 130, 1705-1710.

Evans, C. T., Ratledge, C. (1985) The physiological significance of citric Acid in the control of metabolism in lipid-accumulating yeasts. Biotechnology and Genetic Engineering Reviews, 3, 349-376.

Folch, J., Lees, M., Sloane-Stanley, G.H. (1957). A simple method for the isolation and purification of total lipids from animal tissues. The Journal of Biological Chemistry, 226, 497-509. 
Gustavsson, J., Cederberg, C., Sonesson, U., \& Emanuelsson A. (2013). The methodology of the FAO study: “Global Food Losses and Food Waste - extent, causes and prevention"- FAO, 2011. SIK report No. 857

Harland, B. F., \& Harland, J. (1980). Fermentative reduction of phytate in rye, white and whole wheat breads. Cereal Chemistry, 57, 226-229.

Jin, G., Yang, F., Hu, C., Shen, H., \& Zhao, Z. K. (2012). Enzyme-assisted extraction of lipids directly from the culture of the oleaginous yeast Rhodosporidium toruloides. Bioresource Technology, 111, 378-382.

Koutinas, A. A., Chatzifragkou, A., Kopsahelis, N., Papanikolaou, S., \& Kookos, I. K. (2014). Design and techno-economic evaluation of microbial oil production as a renewable resource for biodiesel and oleochemical production. Fuel, 116, 566-577.

Koutinas, A., Belafi-Bako, K., Babiri-Badr, A., Toth, A., Gubicza, L., \& Webb, C. (2001). Enzymatic hydrolysis of polysaccharides: Hydrolysis of starch by an enzyme complex from fermentation by Aspergillus awamori. Food and Bioproducts Processing, 79, 41-45.

Lee, J. Y., Yoo, C., Jun, S. Y., Ahn, C. Y., \& Oh, H. M. (2010). Comparison of several methods for effective lipid extraction from microalgae. Bioresource Technology, 101, S75S77.

Li, Y. H., Zhao, Z. K., \& Bai, F. W. 2007. High-density cultivation of oleaginous yeast Rhodosporidium toruloides Y4 in fed-batch culture. Enzyme and Microbial Technology, 41, $312-317$.

Lie, S. (1973). The EBC-ninhydrin method for determination of free alpha amino nitrogen. Journal of the Institute of Brewing, 79, 37-41. 
Molina, G. E., Belarbi, E-H., Acien, F. F. G., Robles, M. A., \& Chisti, Y. (2003). Recovery of microalgal biomass and metabolites: process options and economics. Biotechnology Advances, 20, 491-515.

Naik, S. N., Goud, V. V., Rout, P. K., \& Dalai, A. K. (2010). Production of first and second generation biofuels: A comprehensive review. Renewable and Sustainable Energy Reviews, $14,578-597$.

Papanikolaou, S., \& Aggelis, G. (2011). Lipids of oleaginous yeasts. Part I: Biochemistry of single cell oil production. European Journal of Lipid Science and Technology, 113, 10311051.

Ryu, B-G., Kim, J., Kim, K., Choi, Y-E., Han, J-I., \& Yang, J-W. (2013). High-cell-density cultivation of oleaginous yeast Cryptococcus curvatus for biodiesel production using organic waste from the brewery industry. Bioresource Technology, 135, 357-364.

Saenge, C., Cheirsilp, B., Suksaroge, T. T., \& Bourtoom, T. (2011). Potential use of oleaginous red yeast Rhodotorula glutinis for the bioconversion of crude glycerol from biodiesel plant to lipids and carotenoids. Process Biochemistry, 46, 210-218.

Stephenson, A. L., Kazamia, E., Dennis, J. S., Howe, C. J., Scott, S. A., \& Smith, A. G. (2010). Life-cycle assessment of potential algal biodiesel production in the United Kingdom: a comparison of raceways and air-lift tubular bioreactors. Energy \& Fuels, 24, 4062-4077.

Tchakouteu, S. S., Chatzifragkou, A., Kalantzi, O., Koutinas, A. A., Aggelis, G., \& Papanikolaou, S. (2014). Oleaginous yeast Cryptococcus curvatus exhibits interplay between biosynthesis of intracellular sugars and lipids. European Journal of Lipid Science and Technology. DOI: 10.1002/ejlt.201400347

Thiru, M., Sankh, S., \& Rangaswamy, V. (2011). Process for biodiesel production from Cryptococcus curvatus. Bioresource Technology, 102, 10436-10440. 
Tsakona, S., Kopsahelis, N., Chatzifragkou, A., Papanikolaou, S., Kookos, I. K., \& Koutinas, A. A. (2014). Formulation of fermentation media from flour-rich waste streams for microbial lipid production by Lipomyces starkeyi. Journal of Biotechnology, 189, 36-45.

Wiebe, M. G., Koivuranta, K., Penttilä, M., \& Ruohonen, L. (2012). Lipid production in batch and fed-batch cultures of Rhodosporidium toruloides from 5 and 6 carbon carbohydrates. BMC Biotechnology, 12:26.

Wu, S., Hu, C., Jin, G., Zhao, X., \& Zhao, Z. K. (2010). Phosphate-limitation mediated lipid production by Rhodosporidium toruloides. Bioresource technology, 101, 6124-6129.

Wu, S., Zhao, X., Shen, H., Wang, Q., \& Zhao, Z. K. (2011). Microbial lipid production by Rhodosporidium toruloides under sulfate-limited conditions. Bioresource technology, 102, 1803-1807.

Yang, X., Jin, G., Gong, Z., Shen, H., Bai, F., Zhao, Z. K. (2015). Recycling microbial lipid production wastes to cultivate oleaginous yeasts. Bioresource Technology, 175, 91-96.

Zhang, J., Fang, X., Zhu, X-L., Li, Y., Xu, H-P., Zhao, B-F., Chen, L., \& Zhang, X-D. (2011). Microbial lipid production by the oleaginous yeast Cryptococcus curvatus O3 grown in fedbatch culture. Biomass and Bioenergy, 35, 1906-1911.

Zhao, X., Hu, C., Wu, S., Shen, H., \& Zhao, Z. K. (2011). Lipid production by Rhodosporidium toruloides Y4 using different substrate feeding strategies. Journal of Industrial Microbiology and Biotechnology, 38, 627-632. 


\section{Figure legends}

Figure 1 Consumption of glucose $(\boldsymbol{\square})$ and production of TDW ( $\bullet$ ) and microbial lipids $(\boldsymbol{\Delta})$ during batch bioreactor cultures of $R$. toruloides cultivated in (a) heat sterilised and (b) filter sterilised FRW hydrolysates.

Figure 2 Consumption of glucose ( $\boldsymbol{\square})$, FAN ( $\square$ ) and inorganic phosphorus $(\Delta)$ as well as (b) production of TDW (•) and microbial lipids $(\boldsymbol{\Delta})$, and evolution of intracellular microbial lipid content (o) in fed-batch bioreactor culture of $R$. toruloides cultivated in filter sterilised FRW hydrolysate with initial FAN content of $294 \mathrm{mg} / \mathrm{L}$.

Figure 3 Consumption of glucose $(\boldsymbol{\square})$ and production of TDW $(\bullet)$ and microbial lipids $(\boldsymbol{\Delta})$ during fed-batch bioreactor culture of $R$. toruloides following a feeding regime that maintained glucose concentration at $12.2-17.6 \mathrm{~g} / \mathrm{L}$ throughout fermentation

Figure 4 Consumption of glucose ( $\boldsymbol{\square})$ and FAN ( $\square$ ) as well as production of TDW ( $\bullet$ ) and microbial lipids $(\boldsymbol{\Delta})$ during fed-batch bioreactor cultures of $R$. toruloides using intermittent feeding of a hydrolysate containing $700 \mathrm{~g} / \mathrm{L}$ of glucose concentration and around $500 \mathrm{mg} / \mathrm{L}$ of FAN concentration.

Figure 5 Reduction of TDW $(\Delta)$, production of FAN $(\boldsymbol{\Delta})$ and extraction of lipids in the broth $(\bullet$ ) during (a) yeast cell autolysis and (b) hydrolysis of $R$. toruloides cells using crude enzyme produced via SSF of A. awamori. 
Table 1. Effect of different initial C/FAN ratios on $R$. toruloides fed-batch bioreactor culture carried out with FRW hydrolysates and intermittent feeding with a glucose-rich solution

\begin{tabular}{|c|c|c|c|c|c|c|c|}
\hline $\begin{array}{c}\text { C/FAN } \\
(\mathrm{g} / \mathrm{g})\end{array}$ & $\begin{array}{l}\text { TDW } \\
(\mathrm{g} / \mathrm{L})\end{array}$ & $\begin{array}{l}\text { RCW } \\
(\mathrm{g} / \mathrm{L})\end{array}$ & $\begin{array}{l}\text { Lipids } \\
\text { (g/L) }\end{array}$ & $\begin{array}{l}\text { Lipid content } \\
(\%, w / w)\end{array}$ & $\begin{array}{l}\text { Productivity } \\
\quad(g / L \cdot h)\end{array}$ & $\begin{array}{l}\text { Yield* } \\
(\mathrm{g} / \mathrm{g})\end{array}$ & $\begin{array}{c}\text { Specific } \\
\text { growth rate } \\
\left(h^{-1}\right)\end{array}$ \\
\hline 100.4 & $49.0 \pm 4.3$ & $20.9 \pm 4.0$ & $28.2 \pm 0.3$ & $57.5 \pm 4.5$ & $0.22 \pm 0.002$ & $0.14 \pm 0.02$ & 0.205 \\
\hline 80.2 & $61.2 \pm 1.4$ & $23.3 \pm 1.3$ & $37.8 \pm 2.7$ & $61.8 \pm 3.0$ & $0.27 \pm 0.019$ & $0.17 \pm 0.01$ & 0.475 \\
\hline 58.2 & $50.2 \pm 0.3$ & $23.7 \pm 0.1$ & $26.5 \pm 0.3$ & $52.7 \pm 0.4$ & $0.23 \pm 0.003$ & $0.17 \pm 0.01$ & 0.286 \\
\hline 47.2 & $62.2 \pm 1.0$ & $36.3 \pm 0.6$ & $25.9 \pm 0.4$ & $41.6 \pm 0.1$ & $0.19 \pm 0.003$ & $0.11 \pm 0.01$ & 0.261 \\
\hline 31.9 & $57.8 \pm 0.8$ & $31.4 \pm 0.3$ & $26.4 \pm 0.9$ & $45.7 \pm 0.6$ & $0.19 \pm 0.003$ & $0.11 \pm 0.01$ & 0.18 \\
\hline
\end{tabular}


Table 2 Fatty acid composition of lipids produced during fed-batch bioreactor cultures of $R$. toruloides in FWR hydrolysate with initial C/FAN ratio of $80.2 \mathrm{~g} / \mathrm{g}$

\begin{tabular}{|c|c|c|c|c|c|c|c|c|c|}
\hline $\begin{array}{c}\text { Fermentation } \\
\text { time (h) }\end{array}$ & C14:0 & C16:0 & ${ }^{49} \mathrm{C} 16: 1$ & C18:0 & ${ }^{49} \mathrm{C} 18: 1$ & ${ }^{{ }^{49,12} \mathrm{C} 18: 2}$ & ${ }^{{ }^{99,12,15} \mathrm{C} 18: 3}$ & C22:0 & Other \\
\hline 22 & 1.0 & 26.8 & - & 7.6 & 51.5 & 10.7 & 10 & & 0.3 \\
\hline 42 & - & 27.4 & 0.6 & 8.1 & 52.0 & 8.8 & 1.5 & 0.3 & 2.4 \\
\hline 70 & 0.1 & 28.5 & 0.5 & 8.5 & 52.0 & 8.6 & & 0.3 & - \\
\hline 116 & 1.5 & 28.3 & 0.5 & 8.1 & 51.1 & & 1.3 & 0.3 & 0.3 \\
\hline 120 & 1.5 & 28.7 & 0.6 & 7.5 & 50.3 & 9.5 & 1.4 & 0.3 & 0.3 \\
\hline
\end{tabular}



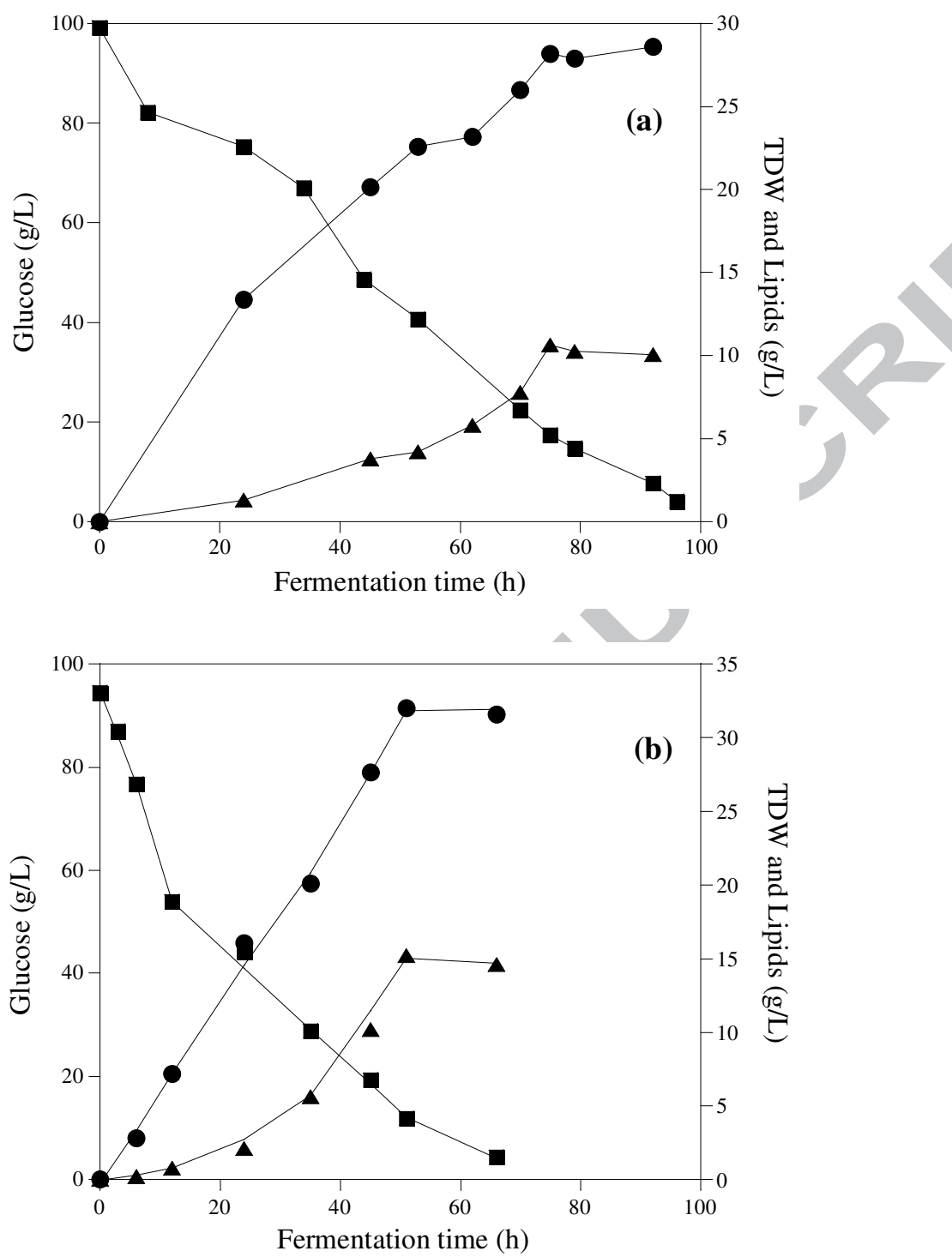

Fig 1 

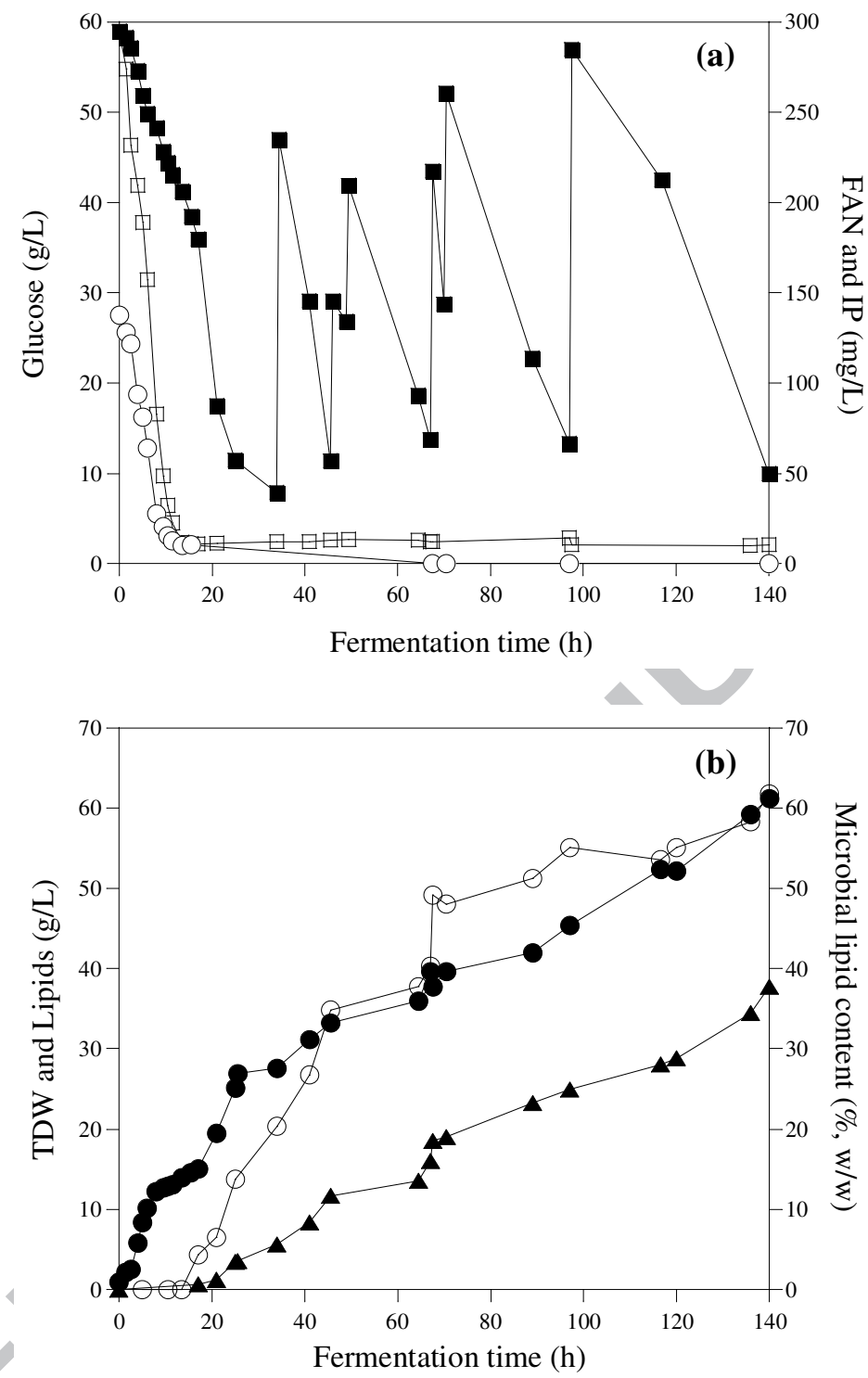

Fig 2 


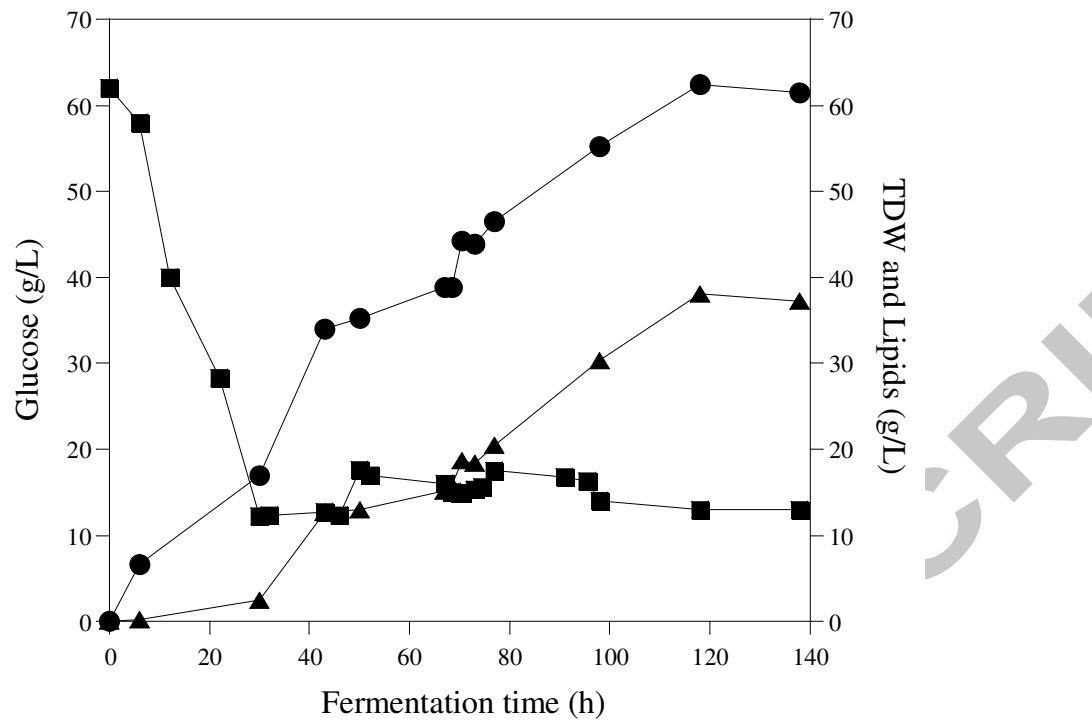

Fig 3 


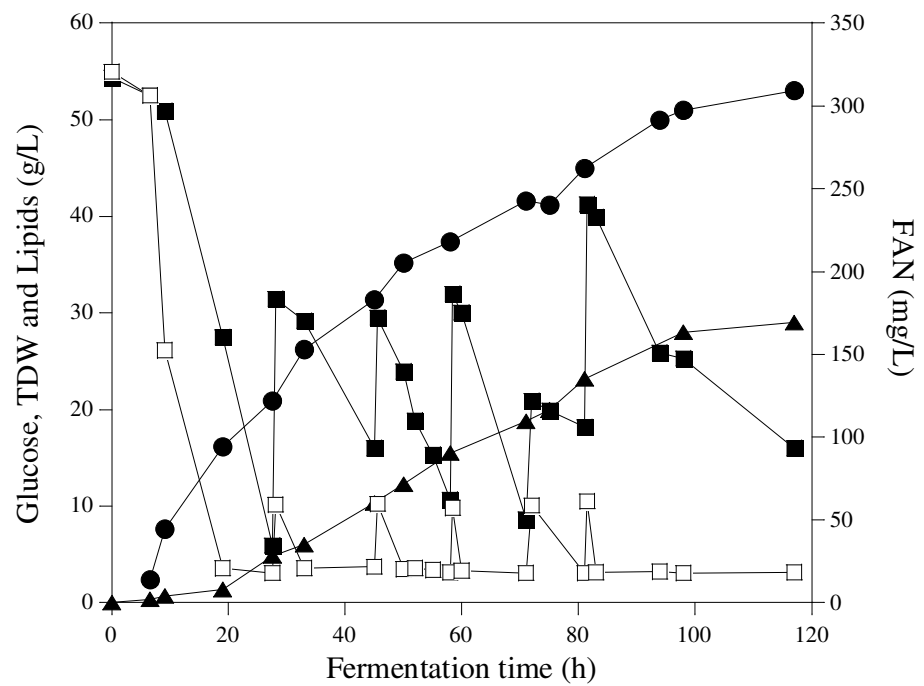

Fig 4 

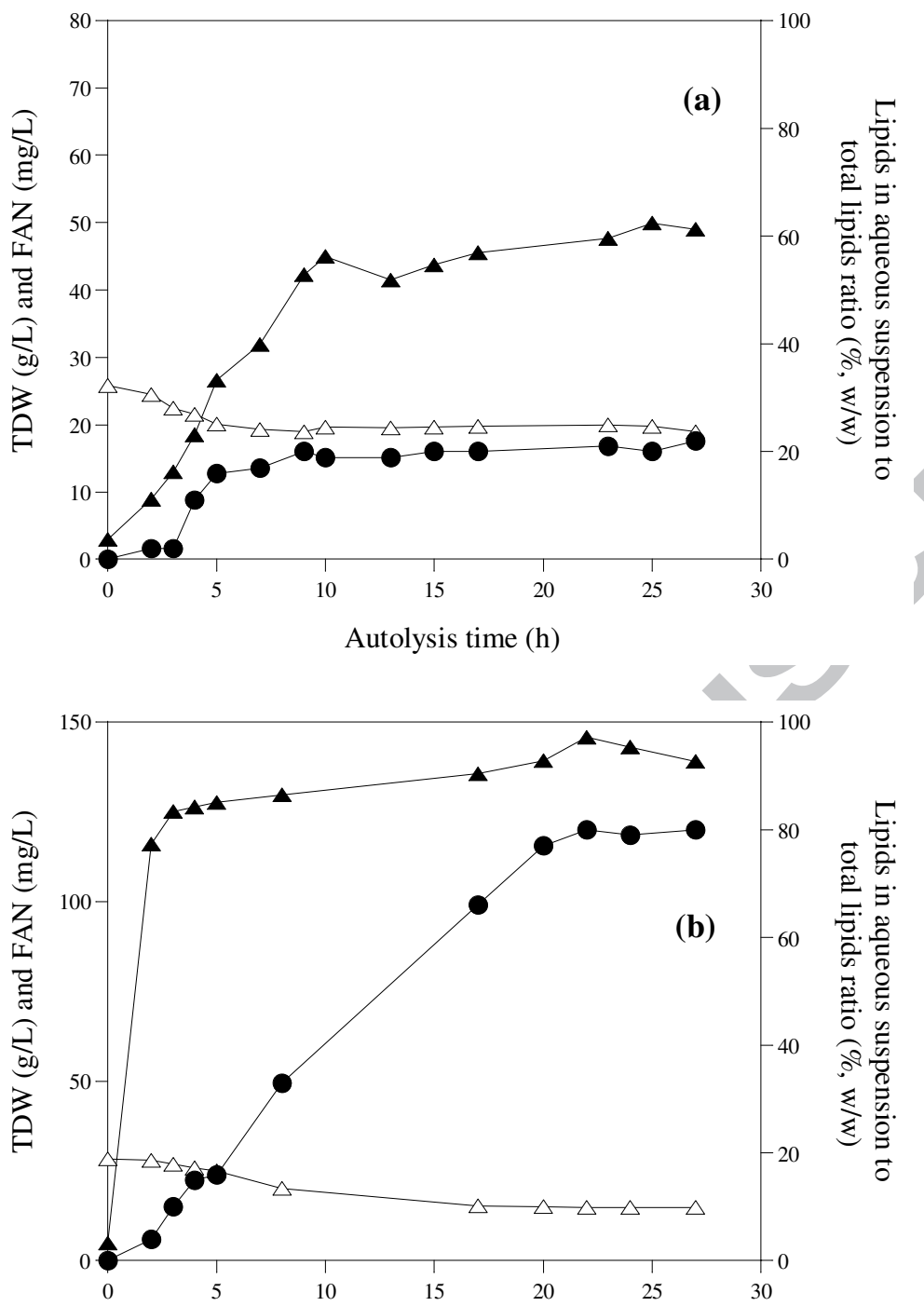

Hydrolysis time (h)

Fig 5 
Dear Editor,

Kindly find below the "Highlights" of the manuscript entitled "Valorisation of side streams from wheat milling and confectionery industries for consolidated production and extraction of microbial lipids" which is submitted for consideration for publication in Food Chemistry, in the Special Issue "Total Food 2014".

Highlights of the manuscript:

- A consolidated process for production and extraction of microbial lipids is proposed

- Filter-sterilized crude hydrolysates were advantageous for biomass and oil production

- Carbon to FAN ratios of crude hydrolysates were optimised in fed-batch cultures

- Fungal crude enzymes were utilised for Rhodosporidium toruloides cell disruption

Yours sincerely

Dr A. Koutinas, Corresponding author 